\title{
Movement deficits and neuronal loss in basal ganglia in TRPC1 deficient mice
}

\author{
Kaiwu He ${ }^{1,2, *}$, Fei $\mathbf{Q i}^{3, *}$, Chunni Guo ${ }^{4}$, Shuqin Zhan ${ }^{5}$, Hua $\mathrm{Xu}^{1}$, Jianjun Liu² and Xifei \\ Yang ${ }^{2}$ \\ ${ }^{1}$ College of Pharmacy, Jinan University, Guangzhou, China \\ ${ }^{2}$ Key Laboratory of Modern Toxicology of Shenzhen, Shenzhen Center for Disease Control and Prevention, Shenzhen, China \\ ${ }^{3}$ Department of Respiratory Medicine, Chinese People's Liberation Army General Hospital, Beijing, China \\ 4 Department of Neurology, Shanghai First People's Hospital Affiliated to Shanghai Jiaotong University, Shanghai, China \\ ${ }^{5}$ Department of Neurology, Xuanwu Hospital of Capital Medical University, Beijing, China \\ * These authors have contributed equally to this work \\ Correspondence to: Xifei Yang, email: xifeiyang@gmail.com
}

Hua Xu, email: huax_mail@126.com

Keywords: TRPC 1; basal ganglia; movement disorder; neuronal loss, Pathology Section

Received: June 29, $2016 \quad$ Accepted: October 03, $2016 \quad$ Published: October 11, 2016

\section{ABSTRACT}

Transient receptor potential cation (TRPC) channel proteins are abundantly expressed in brain. However, the functions of these TRPC proteins such as TRPC1 are largely unclear. In this study, we reported that TRPC1 deficiency caused movement disorder as measured by swimming test, modified open field test and sunflower seeds eating test. Immunofluorescent staining showed significant loss of both NeuN-positive cells and tyrosine hydroxylase (TH) -positive cells in the caudate putamen ( $\mathrm{CPu}$ ), the external globus pallidus (GPe), and the substantia nigra pars reticulata (SNr) in 5-month-old TRPC1 knockout mice (TRPC1 ${ }^{-/-}$) compared to the wild type (WT) mice. TUNEL staining further revealed that TUNEL-positive cells were significantly increased in the $\mathrm{CPu}, \mathrm{GPe}$, and $\mathrm{SNr}$ of TRPC1 ${ }^{-/-}$mice. Taken together, these data suggests that TRPC1 is involved in the control of motor function by inhibiting the apoptosis of neuronal cells of basal ganglia.

\section{INTRODUCTION}

The basal ganglia are a group of subpalial nuclei which have an important part in motor, emotional, and cognitive functions. Though the term "basal ganglia" has been defined in many different ways, we choose to restrict the meaning to include only the caudate putamen $(\mathrm{CPu})$, the external globus pallidus (GPe), and the substantia nigra pars reticulata $(\mathrm{SNr})$ [1]. The involvement of $\mathrm{CPu}$, $\mathrm{GPe}$, and $\mathrm{SNr}$ in movement disorders in neurological diseases, such as Parkinson's disease and Huntington's disease was widely investigated [2-6]. Previous studies have proposed that basal ganglia circuits are involved in the regulation of purposeful voluntary movement and various functions $[7,8]$, and dysfunction of basal ganglia leads to movement disorders [9]. Thus, it is important to find some methods of animal models to investigate the pathophysiology of these diseases and screen potential treatments. Although many species have been used to develop experimental models, such as zebrafish [10, $11]$, rat [12, 13], and primates [14], mouse has become the focus of studies on the function of genes. Up to date, the effects of basal ganglion on movement function and the specific molecular mechanisms remain elusive. The transient receptor potential (TRP) channel superfamily is composed of a set of non-selective cation channels that are responsible to respond to the changes in the external environments. TRP channels compose of several groups that include the TRPC, TRPV, TRPM, etc $[15,16]$. TRPC1 was highly expressed in endoplasmic reticulum (ER) [17]. ER $\mathrm{Ca}^{2+}$ ion is critical for the regulation of protein translation and some other molecular processes [18]. $\mathrm{ER} \mathrm{Ca}^{2+}$ dishomeostasis, including $\mathrm{ER} \mathrm{Ca}^{2+}$ depletion or inhibition of N-linked glycosylation, causes abnormal accumulation of unfolded proteins, thus triggering ER stress [19]. Moreover, changes in $\mathrm{Ca}^{2+}$ in ER or mitochondria were able to influence neuronal survival [20]. $\mathrm{ER} \mathrm{Ca}^{2+}$ depletion activates the store-operated $\mathrm{Ca}^{2+}$ 
(SOC) entry and thus triggers $\mathrm{Ca}^{2+}$ entry from the external media via the store-operated $\mathrm{Ca}^{2+}$ entry (SOCE) $[21,22]$. SOC-mediated $\mathrm{Ca}^{2+}$ entry, a critical process to maintain ER $\mathrm{Ca}^{2+}$ levels, is significantly correlated with TRPC1. Although the molecular identity of the SOCE channel is not yet determined, TRPC1 has been demonstrated to be activated by store depletion per se [23, 24]. Moreover, TRPC1 is important for some critical biological and pathological processes such as cell proliferation, axonal guidance, and apoptosis. TRPC $1^{-/}$mice has widespread loss of DA neurons and brain tissues of PD patients also show a decreased TRPC1 levels [25]. Besides, TRPC1 is also widely expressed in many regions of the brain such as cerebral cortex, hippocampus, cerebellum, amygdale and in the substantia nigra $[26,27]$, indicaitng that TRPC1 could have significance in the survival and function of neuronal cells.

In this work, we studied the influence of TRPC1 depletion on motor function and neuronal survival in mice. These data revealed that movement deficits and widespread neuronal loss including dopaminergic (DA) neurons in basal ganglia in TRPC1 $1^{-/}$mice.

\section{RESULTS}

\section{Movement disorder was caused by TRPC1 depletion}

In order to determine the effect of TRPC1 depletion on motor ability of mice in deep water, swimming test was performed. We measured the total distance traveled and the average velocity of the mice. TRPC $1^{-/}$mice showed reduced total traveled distance $(P<0.001)$ (Figure 1a) and decreased average velocity $(P<0.001)$ (Figure 1b) relative to the WT mice. These data suggested that TRPC1 depletion impaired the motor ability of mice in deep water.

In order to determine the effect of TRPC1 depletion on spontaneous locomotor activity of the mice, modified open field test was performed. We found significant differences in the total traveled distance (Figure $2 a$ ) and the average movement speed (Figure $2 b$ ) between the two groups. The traveled distance and average velocity were significantly decreased in TRPC $1^{-/}$mice compared to the WT mice $(P<0.01)$. However, no significant difference in the time of the immobility of the mice was observed in $\mathrm{TRPC}^{-/-}$mice compared to the WT mice (Figure 2c). These data suggested that TRPC1 depletion impaired the spontaneous locomotor activity of the mice.

In order to determine the effect of TRPC1 depletion on the skilled movement of the mice, sunflower seeds eating test was performed. As shown in Figure 3, TRPC1 ${ }^{-}$ - mice ate significantly fewer sunflower seeds during the observation period compared to the WT mice $(P<0.001)$. Furthermore, the eaten sunflower seeds by TRPC1 $1^{-/}$mice displayed significant bite marks. These data indicated that TRPC1 impaired the skilled movement ability of the mice.

\section{The effect of TRPC1 depletion on neuronal survival in basal ganglia}

In order to determine the effect of TRPC1 depletion on neuronal survival in basal ganglia, i.e. the areas $\mathrm{CPu}, \mathrm{GPe}$, and SNr. Immunofluorescence staining was performed using neuron-specific marker NeuN. The data showed that the number of NeuN-positive cells was significantly decreased in $\mathrm{GPe}$ and $\mathrm{SNr}$ of $\mathrm{TRPC}^{-/}$mice relative to the WT mice $(P<0.01)$ (Figure $4 \mathrm{a}, 4 \mathrm{c}, 4 \mathrm{~d}$ ),
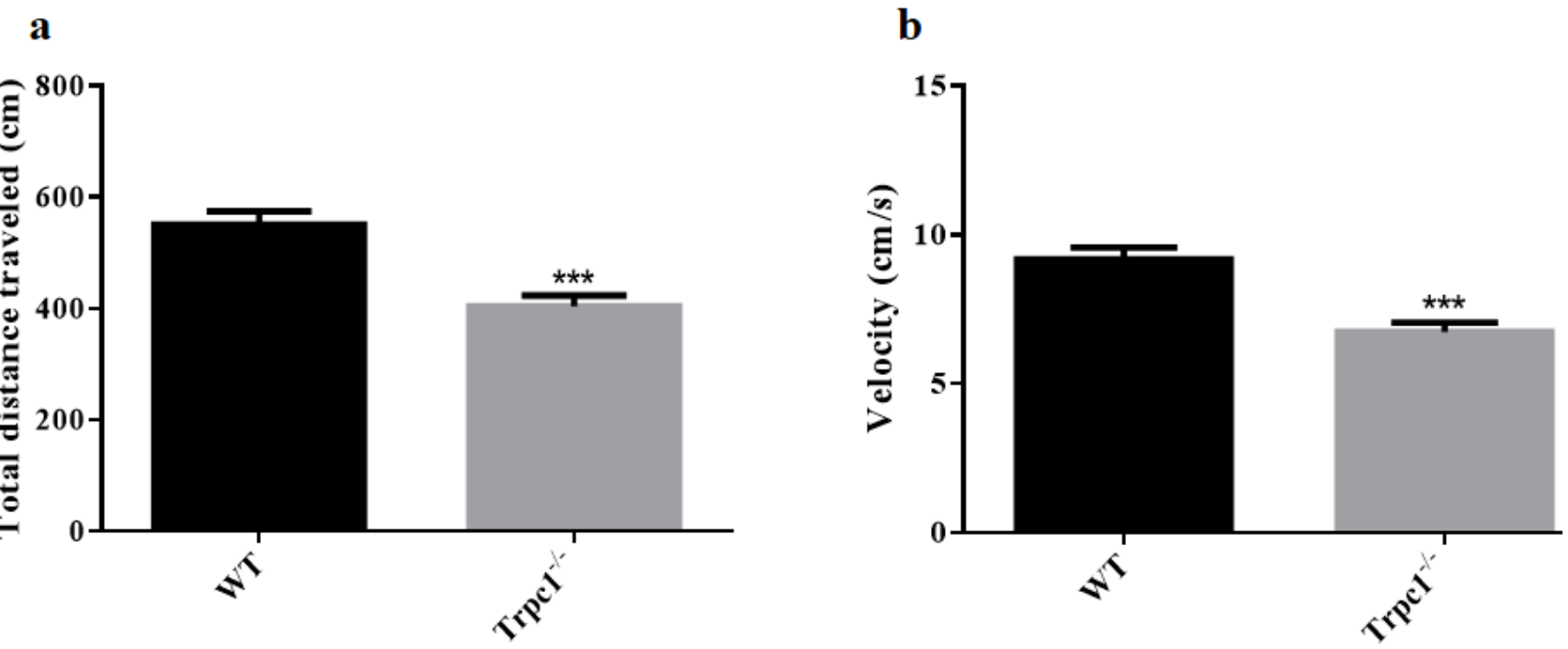

Figure 1: The Movement ability in deep water was measured by swimming test. a. The total distance traveled; b. The average velocity. The data were presented as mean \pm SEM. ${ }^{* * *} P<0.001, v s$. WT. $n=9$ for each group. 

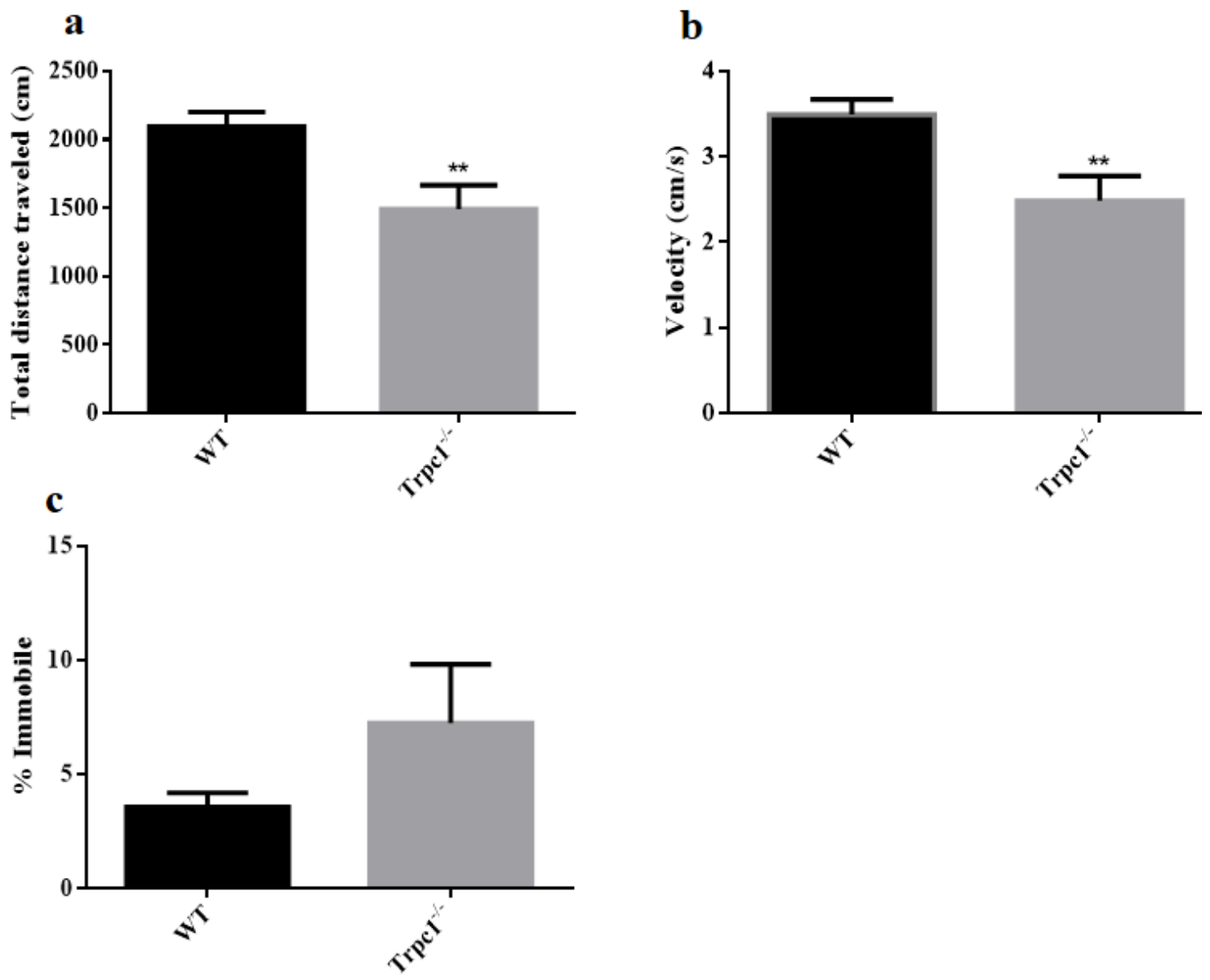

Figure 2: Spontaneous locomotor activity was measured by modified open field. $\mathbf{a}$. The total distance traveled; $\mathbf{b}$. The average velocity; c. The time of immobility. The data were presented as mean $\pm \mathrm{SEM}$. ${ }^{* *} P<0.01, v s$. WT. $n=9$ for each group.

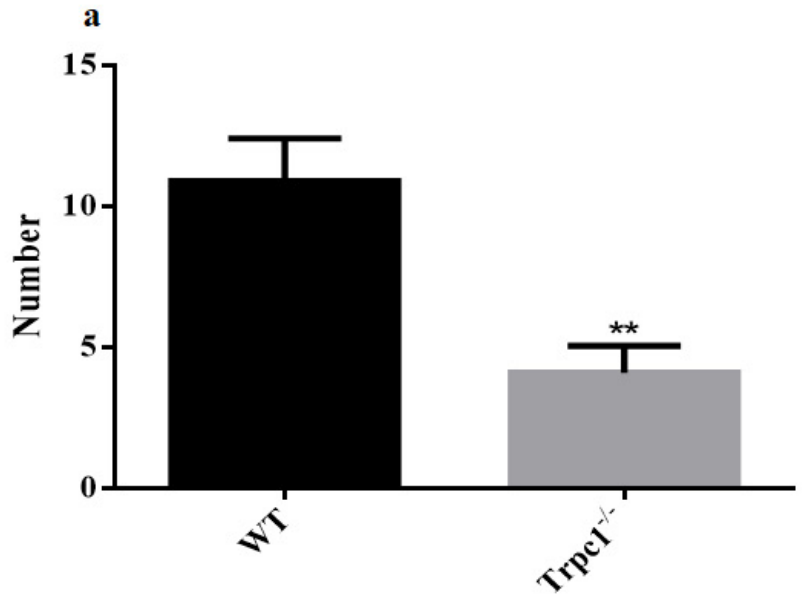

b

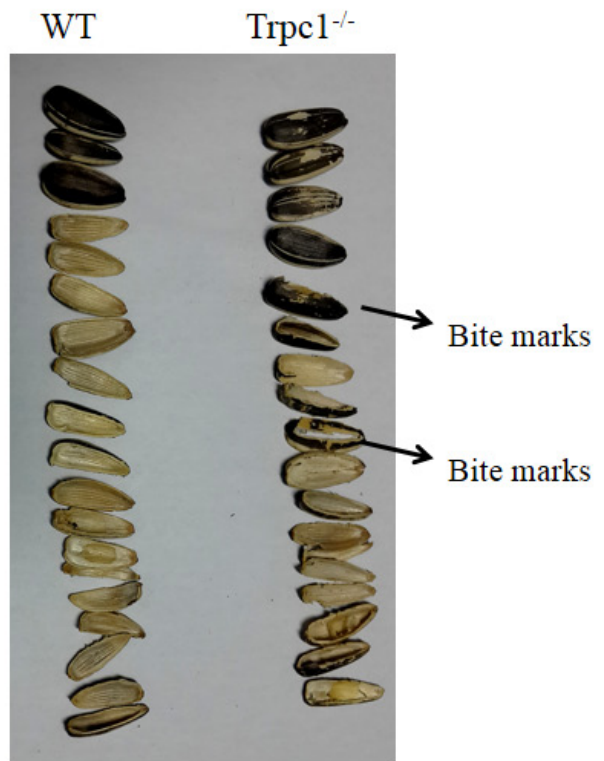

Figure 3: The skilled movement was measured by sunflower seeds eating test. a. Changes the number of sunflower seeds eaten by the mice during $24 \mathrm{~h}$. b. The morphological of sunflower seeds eaten by the mice during $24 \mathrm{~h}$. The data were presented as mean $\pm \mathrm{SEM}$. ${ }^{* *} P<0.01$, vs. WT. $n=10$ for each group. 
while there was no significant difference of the number in area $\mathrm{CPu}$ between the groups (Figure 4a, 4b). These data suggested that TRPC1 depletion caused neuronal loss to some extent in basal ganglia, indicating that TRPC1 is required for the survival of neurons in basal ganglia.
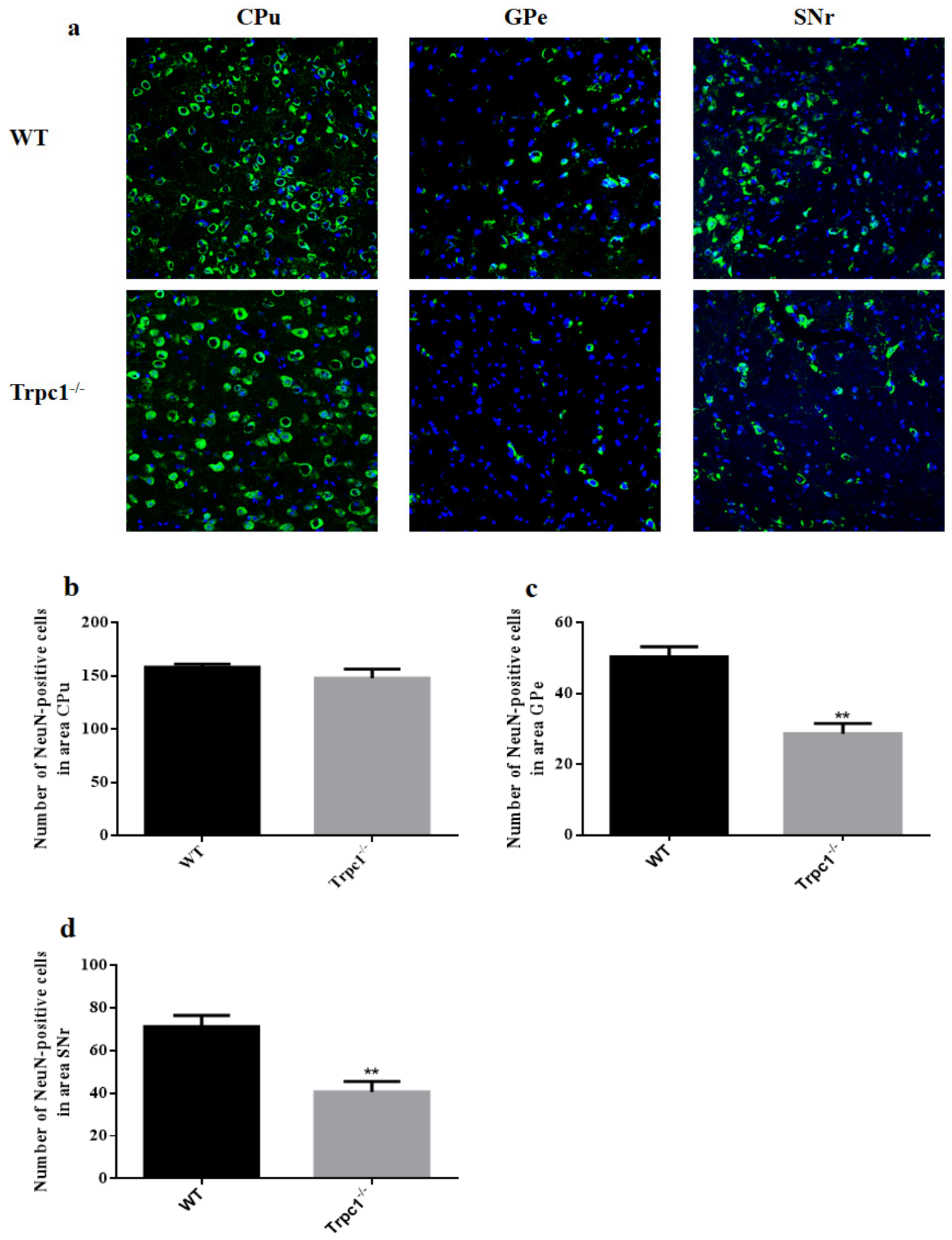

Figure 4: TRPC1 depletion caused neuronal loss in basal ganglia. a. Immunofluorescent images representing the number of neurons as evidenced by NeuN-staining; b. The number of NeuN-positive cells in CPu; c. The number of NeuN-positive cells in GPe; $\mathbf{d}$. The number of NeuN-positive cells in SNr. The data were presented as mean \pm SEM. ${ }^{* *} P<0.01, v s$. WT. $n=3$ for each group. Scale bar $=100 \mu \mathrm{m}$. 
The effect of TRPC1 depletion on the survival of DA neurons in basal ganglia

In order to determine the effect of TRPC1 depletion on the survival of DA, we performed immunofluorescence using tyrosine tydroxylase (TH) antibody, a maker of DA neurons. We found that TRPC1 1 mice showed significant loss of TH-positive cells relative to the WT mice in $\mathrm{CPu}$ $(P<0.05)$ (Figure 5a, 5b), and the number of TH-positive cells was also significantly decreased in $\mathrm{GPe}$ and $\mathrm{SNr}$ $(P<0.01)$ (Figure 5a, 5c, 5d). These data suggested that TRPC1 depletion caused loss of DA neurons in basal ganglia.

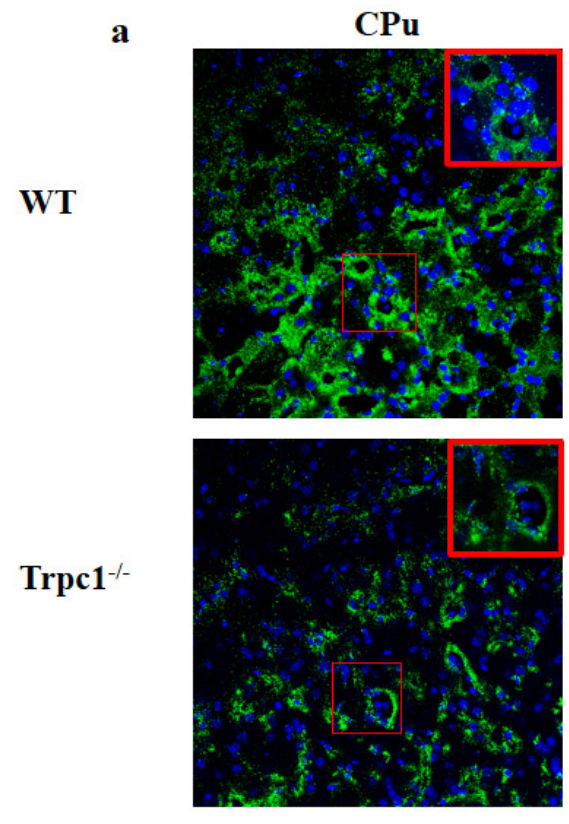

b
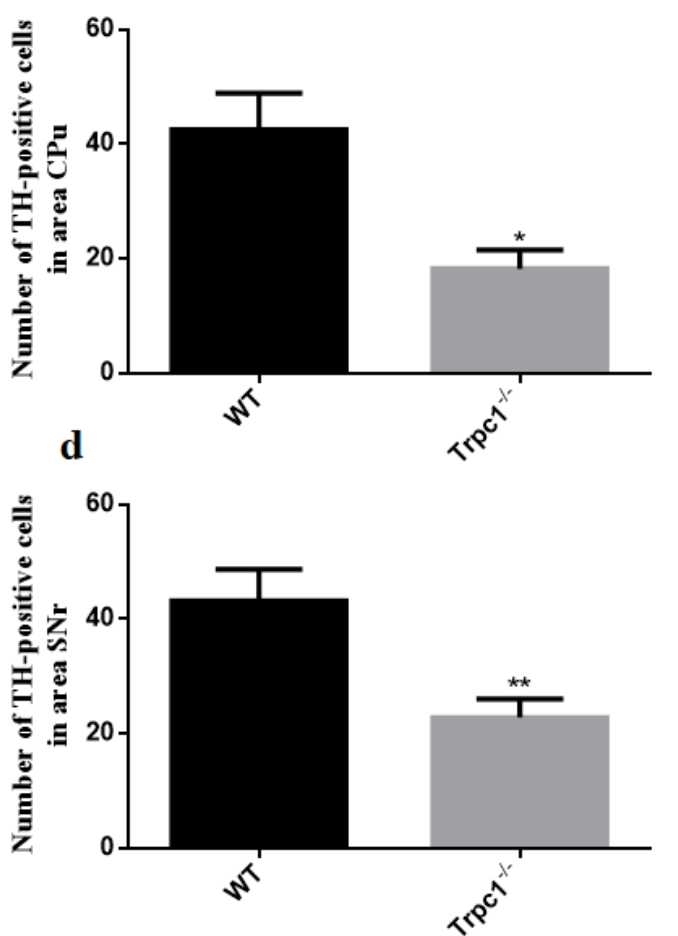

GPe
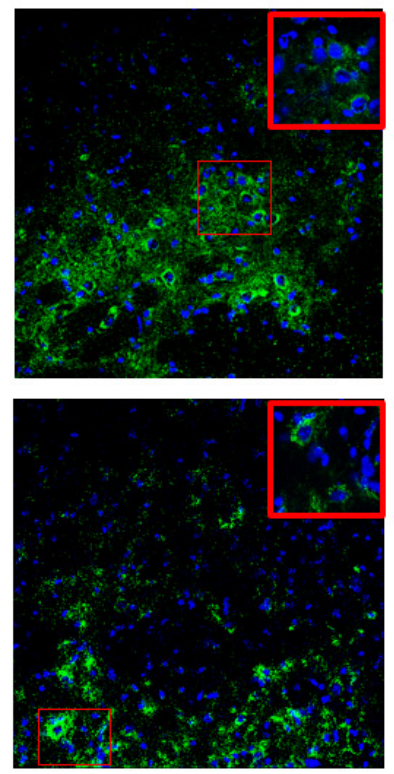

c
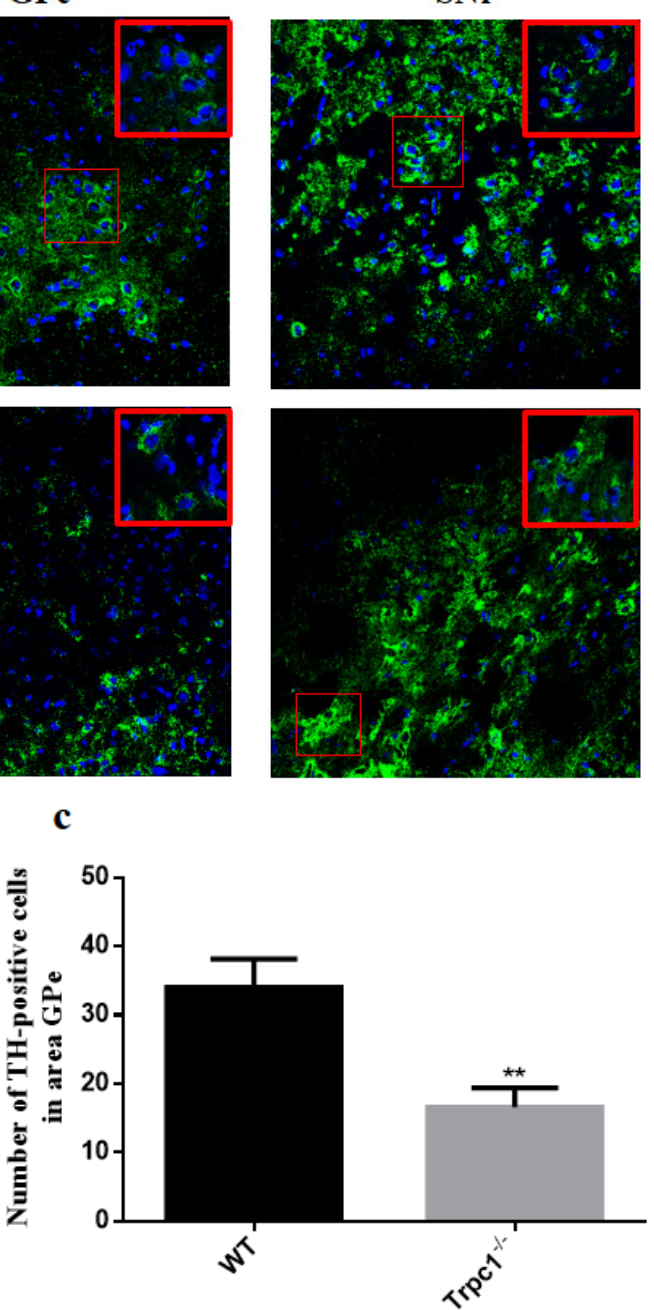

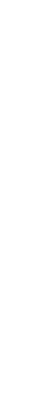


TRPC1 deficiency caused neuronal apoptosis in basal ganglia

In order to determine the effect of TRPC1 depletion on apoptosis, we performed TUNEL staining to measure the change of apoptosis in basal ganglia. The data showed significantly increased TUNEL-positive cells in $\mathrm{CPu}(P<$ $0.05)$, GPe and $\mathrm{SNr}(P<0.01)$ of TRPC1 ${ }^{-/}$mice compared with the WT mice (Figure 6a-6d), suggesting that neuronal loss caused by TRPC1 depletion may be a consequence of neuronal apoptosis in basal ganglia.

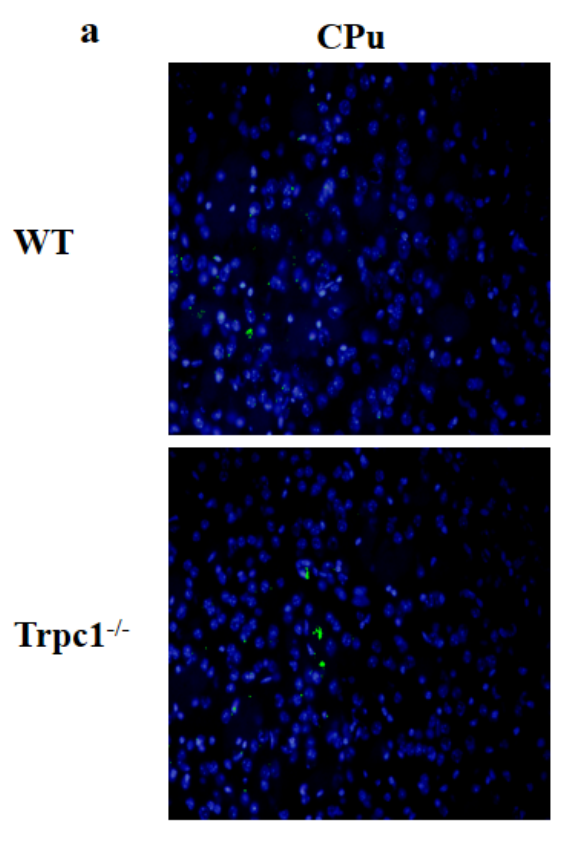

b
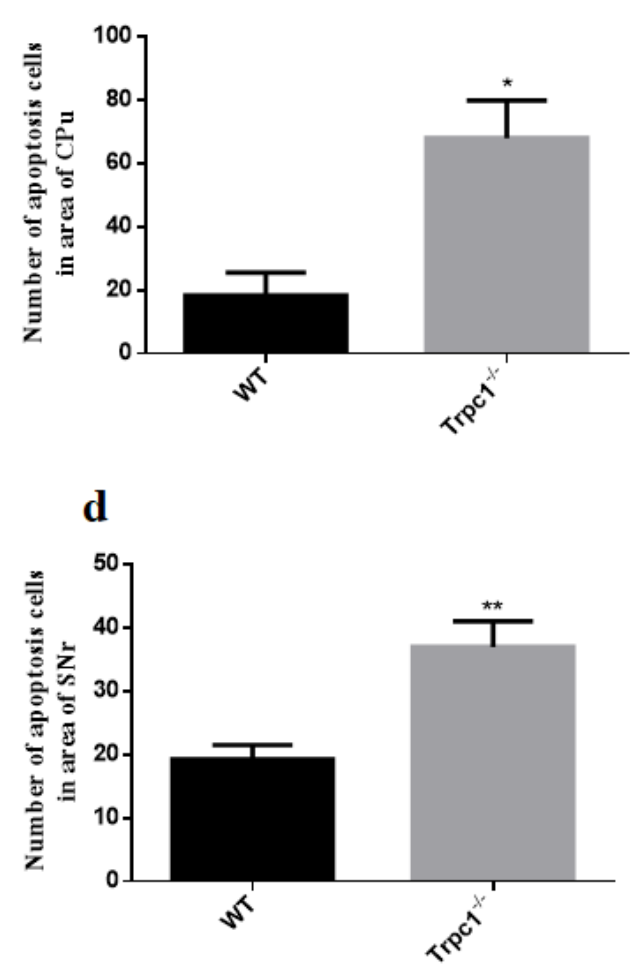
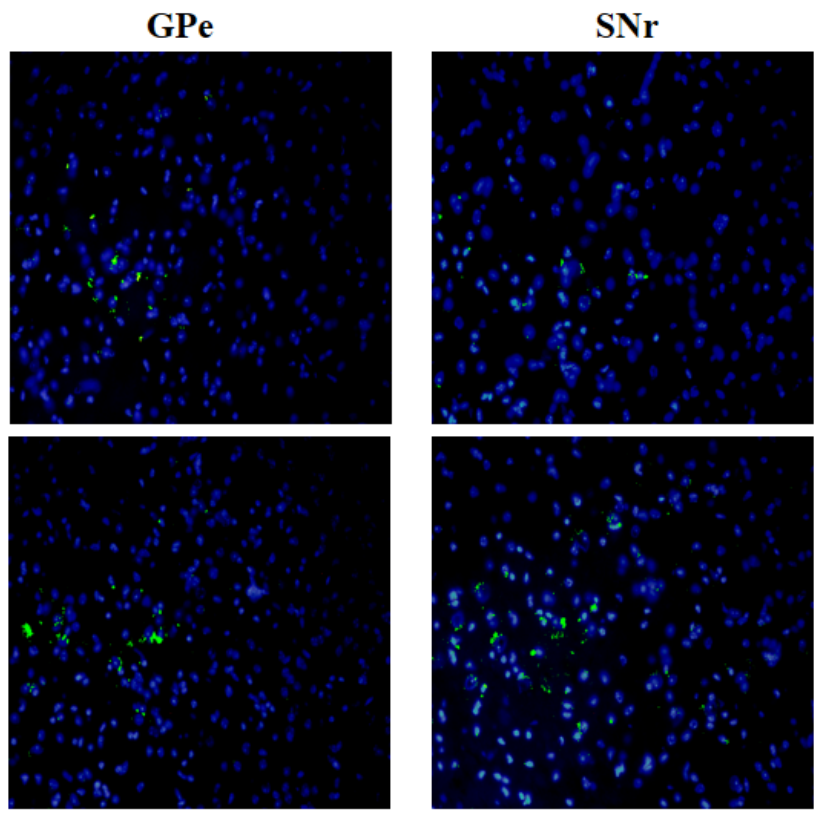

c

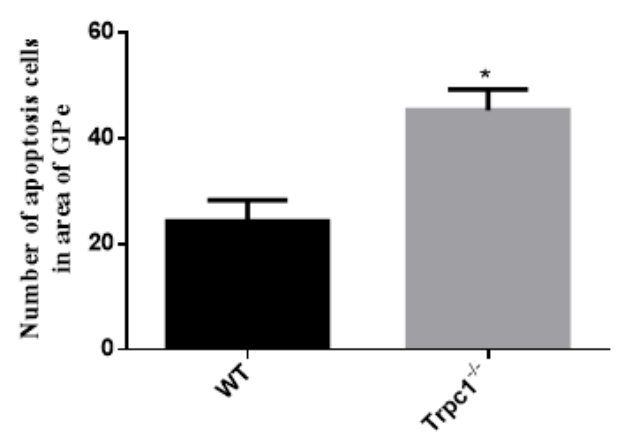

Figure 6: TRPC1 depletion caused neuronal apoptosis in basal ganglia. a. A representative image of neuronal apoptosis in basal ganglia; b. The number of apoptotic cells in $\mathrm{CPu} ; \mathbf{c}$. The number of apoptotic cells in GPe; $\mathbf{d}$. The number of apoptotic cells in SNr. ${ }^{*}$ and ${ }^{* *} P<0.05$ and $P<0.01, v s$ WT, respectively. The data were presented as mean \pm SEM. $n=3$ for each group. Scale bar $=100 \mu \mathrm{m}$. 


\section{DISCUSSION}

Previous studies have shown that TRPC1 is vital for neuronal survival $[27,28]$, indicating that TRPC1 may be involved in the regulation of motor activity. In this study, we demonstrated that depletion of TRPC1 caused movement disorder of mice and the loss of NeuN neurons and DA neurons in basal ganglia, including the area of $\mathrm{CPu}, \mathrm{GPe}$ and $\mathrm{SNr}$.

The behavioral tests, i.e. swimming test, modified open field test, and sunflower seeds eating test, consistently demonstrated that TRPC1 depletion caused movement disorder in mice. Motor function in swimming activity requires a different set of muscles, spinal reflexes, and brain regions, which is different from the movement function involved in locomotion, wheel running and some other motor behaviors [29]. Additionally, there are two major disadvantages for swimming test of movement function: (i) the animals may drown in highly immobile state; (ii) swimming in cold water may trigger stress, and may affect the outcome [30]. In this study, we maintained the water temperature at $24 \pm 2^{\circ} \mathrm{C}$ to overcome this problem. Simultaneously, TRPC $1^{-/}$mice showed DA neuronal loss in the $\mathrm{SNr}$, a brain region closely linked with PD [25].

Spontaneous activity of animals was measured by modified open field test which had been used to assess basal ganglia related movement disorder in mice [31]. The advantages of this method were as follows: (i) weak light environment was more aligned with living habit of the mice, then more conducive to free moving, (ii) the 20 minutes travelling increased the difficulty of movement, thus making the differences in motor function more obvious. Sunflower seeds eating was used to assess skilled movement function. Normal mice executed skilled movement with seemingly effortless precision, depending on elaborate series of neural transformations by the interaction of different neurons especially DA neuron [32]. Our present study showed that TRPC1 depletion impaired the movement function of the mice, especially skilled movement function. Besides, previous studies also demonstrated that TRPC1 depletion could cause spatial memory impariment of mice [33].

NeuN is widely used as a neuronal marker [34]. NeuN was reported to be significantly reduced in SOD1 mice with movement deficit [35]. Additionally, BDNF could promote survival of basal ganglia neurons and its progressive loss had been shown in neurodegenerative diseases such as HD [35]. Thus to some extent, the decrease of NeuN neurons could reflect down-regulation of BDNF. In our study, NeuN neurons were significantly decreased in $\mathrm{GPe}$ and $\mathrm{SNr}$ areas of $\mathrm{TRPC}^{-/}$mice compared to the WT mice. Taken together, NeuN neurons may be necessary for motor functions.

Another important finding in the present study was that histopathological analysis demonstrated significant loss of DA neurons in basal ganglia of TRPC $1^{-/}$mice, including the $\mathrm{CPu}, \mathrm{GPe}$, and $\mathrm{SNr}$ areas. In ${\mathrm{c}-\mathrm{rel}^{-/}}^{-/}$mice, researchers found that motor deficits was observed responsive to L-DOPA treatment, which was associated with DA neuronal loss in the $\mathrm{SNr}$ [36].Besides, injection of 6-OHDA into the $\mathrm{CPu}$ area caused motor impairment, and rats with combined DA neurons lesions were more prone to suffering dyskinesia [37]. These data indicated that DA neurons in basal ganglia especially the GPe and $\mathrm{SNr}$ area played a vital role in the regulation of motor function. The GPe area was critical for the regulation of motor function, and a previous study also showed that DA neuron-depletion in the GPe area induced significant movement impairment [38]. In our study, TRPC1 depletion was shown to cause movement disorder in the mice, which could be a consequence of the loss of the DA neurons in basal ganglia caused by TRPC1 depletion.

To further determine whether the neuronal loss was related to apoptosis, we evaluated the effects of TRPC1 depletion on neuronal apoptosis using TUNEL staining. The results showed that TRPC1 depletion could increase the number of TUNEL-positive neuronal cells in basal ganglia, suggesting that neuronal loss caused by TRPC1 depletion as observed may result from neuronal apoptosis. Besides, a study reported that TRPC1 could prevent human SH-SY5Y cells from cytotoxicity by inhibiting cellular apoptosis [39]. In some neurodegenerative diseases such as $\mathrm{AD}$ and $\mathrm{PD}$, apoptosis is the main cause leading to neuronal death [40], and preventing apoptotic processes is a strategy for the treatment of these diseases [41, 42]. Thus, it was indicated that the loss of DA neurons, resulting from cell apoptosis, consequently caused movement disorder by TRPC1 depletion.

In summary, this study demonstrated that TRPC1 depletion caused movement disorder in mice and neuronal loss including DA neurons in basal ganglia. TUNEL staining indicated that neuronal apoptosis may contribute to neuronal loss. Our data suggested that TRPC1 was involved in the control of motor function by regulating the survival of neuronal cells of basal ganglia.

\section{MATERIALS AND METHODS}

\section{Animals}

The TRPC1 1 mice were obtained from Prof. Lutz Birnbaumer (NIEHS, US) and the wild type (WT) mice were purchased from Vital River Laboratory Animal Technology Co. Ltd (Beijing, China). A total of thirty mice at 5 months old were used in this study. All the mice were randomly divided into WT mice and TRPC $1^{-/-}$mice. The mice were housed in groups of 15 mice per cage $(470 \times 350 \times 200 \mathrm{~mm})$, and kept under controlled light and environmental conditions (12-hour light / 12-hour dark 
cycle with light on from 6: 00 am to 18: 00 am at a constant temperature of $24 \pm 2{ }^{\circ} \mathrm{C}$ and humidity) with free access to food and water. Animal treatment and care procedures were performed following the National Institutes of Health Guide for the Care and Use of Laboratory Animals (NIH publications no. 80-23) and the Regulations for Animal Care and Use Committee of Experimental Animal Center at Shenzhen Center for Disease Control and Prevention. All efforts were made to minimize animal suffering and reduced the number of mice used.

\section{Swimming test}

The mice were subjected to the swimming test as previously described [29]. The behavioral test was carried out in a circular pool (height $30 \mathrm{~cm}$, diameter $120 \mathrm{~cm}$ ) filled with water (temperature of $24 \pm 2{ }^{\circ} \mathrm{C}$ ) to a level that prevented the mice from touching the bottom. The mouse was placed in a fixed position in the pool, facing the tank wall, then was released into the water at the waterlevel (not dropped). After $1 \mathrm{~min}$, the mouse was wiped dry immediately using a dry cloth and returned to a cage to have 1-min break. The test was repeated 4 times. The pathway that the mice went through was recorded by a video camera that was connected with a digital-tracking instrument attached to the computer loaded with the software (Huaibei Zhenghua Biologic Apparatus Facilities Limited Company, Huaibei, Anhui, China).

\section{Modified open field test}

The experiment was performed in a sound proof, weak light environment as previously described [43]. The apparatus consisted of a rectangular area of $50 \times 50 \mathrm{~cm}$, with plastic walls of $40 \mathrm{~cm}$ height and white floor that was divided equally into 16 compartments. The animals were placed individually in one corner of the open field, facing the center. Each mouse was in the area for a total of $20 \mathrm{~min}$, with $10 \mathrm{~min}$ for acclimation, and $10 \mathrm{~min}$ for data acquisition. The total distance traveled, the average velocity, and the time of immobility were calculated. After each test, the apparatus was cleaned with $75 \%(\mathrm{v} / \mathrm{v})$ alcohol to avoid the residual odor.

\section{Sunflower seeds eating test}

Sunflower seeds eating test was used to assess skilled movement ability. Before the formal experiment, each mouse was placed into a single cage in order to adapt to the new environment. Then sunflower seeds eaten by the animals were analyzed. On the first day, 20 sunflower seeds were put into each cage. After $24 \mathrm{~h}$, the number of seeds was recorded and the morphological of the sunflower seeds were analyzed.

\section{Sample preparation for tissue sections}

After behavioral tests, the mice were anesthetized with 4\% chloral hydrate and perfused via the left cardiac ventricle with $0.9 \% \mathrm{NaCl}$, followed by $4 \%$ (w/v) paraformaldehyde fixative in $0.1 \mathrm{M}$ phosphate buffer solution $(\mathrm{pH}=7.4)$, then the brains were removed and stored in $4 \%(\mathrm{w} / \mathrm{v})$ paraformaldehyde fixative at $4{ }^{\circ} \mathrm{C}$ for $18 \mathrm{~h}$. The whole brains were placed in a $30 \%$ sucrose solution in $0.1 \mathrm{M}$ phosphate buffer solution for further use.

After fully fixation, the tissues were embedded in O. C. T. compound (Leica Cat. No. 14020108926), and subjected to cryosectioning at a thickness of $15 \mu \mathrm{m}$. Continuous cryosectioned slices were placed on $0.1 \mathrm{M}$ phosphate buffer solution ( $\mathrm{pH}=7.4$ ), and were selectively mounted on adhesion microscope slides (CITOGLAS. Ref $188105 \mathrm{~W}$ ) according to different experimental requirements ( $\mathrm{CPu}$ or $\mathrm{GPe}$ or $\mathrm{SNr})$, to minimize sample variations. The collected sections were stored at $-20{ }^{\circ} \mathrm{C}$ until further use.

\section{Immunofluorescent staining}

Immunofluorescence staining was performed as previously described [44]. In brief, $15 \mu \mathrm{m}$-thick coronal sections were rinsed in PBS 4 times for $5 \mathrm{~min}$. The sections were blocked for $60 \mathrm{~min}$ in blocking buffer solution $\left(1 \times \mathrm{PBS} / 5 \%\right.$ normal serum / $0.3 \%$ Triton ${ }^{\mathrm{TM}}$ $\mathrm{X}-100)$. Primary antibodies used were against AntiNeuN (rabbit monoclonal, diluted 1:500) and tyrosine hydroxylase (TH) (rabbit polyclonal, diluted 1:200) (both Cell Signaling Technology, USA). Incubation with primary antibodies were performed overnight at $4{ }^{\circ} \mathrm{C}$ in primary antibody dilution buffer $(1 \times \mathrm{PBST}$ with $5 \%$ BSA). After being washed with PBST, the sections were stained with the secondary antibody, Alexa Fluor ${ }^{\circledR}-488$ goat anti-rabbit (Invitrogen) (1:500). The sections were incubated for $1 \mathrm{~h}$ in the dark at room temperature, then stained with DAPI (Beyotime Institute of Biotechnoloy, Haimen, China) for $1 \mathrm{~min}$ to reveal the nuclei. The brain sections were examined under a laser scanning confocal microscope (Leica, Wetzlar, Germany).

\section{TUNEL staining}

For the detection of apoptosis, TUNEL staining was performed to determine neuronal apoptosis using the DeadEnd ${ }^{\mathrm{TM}}$ Fluorometric TUNEL System (Promega). Briefly, the brain sections were immersed in $0.85 \% \mathrm{NaCl}$ for $5 \mathrm{~min}$ and washed with $1 \times \mathrm{PBS}$ for $5 \mathrm{~min}$ at room temperature, then the sections were fixed by immersing in $4 \%$ paraformaldehyde fixative for $15 \mathrm{~min}$ and washed with $1 \times$ PBS for $5 \mathrm{~min}$. After the excess liquid was removed, the sections were treated with $100 \mu \mathrm{l}$ of the $20 \mu \mathrm{g} / \mathrm{ml}$ 
proteinase $\mathrm{K}$ to each slide and incubated for $10 \mathrm{~min}$ at room temperature. While the sections were equilibrating, the Nucleotide Mix was on ice and sufficient rTdT incubation buffer were prepared for all experimental reactions, then $50 \mu \mathrm{l}$ rdT incubation buffer was added to each slide. The sections were covered with plastic coverslips to ensure even distribution of the reagent. The DNA fragments were labeled with the $\operatorname{rTdT}$ at $37{ }^{\circ} \mathrm{C}$ for $1 \mathrm{~h}$ in the dark. The sections were stained with DAPI for $3 \mathrm{~min}$ and observed by a microscope (Olympus 1 X51, Tokyo, Japan).

\section{Statistical analysis}

Statistical analysis was performed using GraphPad Prism 6.0 statistical software (GraphPad Software, Inc.). The significance of the differences between the groups was determined by unpaired $t$-test. The data were expressed as mean \pm standard error (SEM). The level of significance was set at $P<0.05$.

\section{ACKNOWLEDGMENTS}

This work was supported by NSFC (the National Natural Science Foundation of China) (81673134, 81501213, 81571294), Guangdong Provincial Natural Science Foundation (2014A030313715, 2016A030313051), Guangdong Provincial Scheme of Science and Technology (To X.F.Y), and Shenzhen Special Fund Project on Strategic Emerging Industry Development (JCY20160428143433768， JCYJ20150529164656093, JCYJ20150529153646078).

\section{CONFLICTS OF INTEREST}

There is no conflict of interests to disclose.

\section{REFERENCES}

1. Bechard AR, Cacodcar N, King MA and Lewis MH. How does environmental enrichment reduce repetitive motor behaviors? Neuronal activation and dendritic morphology in the indirect basal ganglia pathway of a mouse model. Behavioural brain research. 2016; 299:122-131.

2. Morari M and Fantin M. Loss of the preferential control over the striato-nigral direct pathway by striatal NMDA receptors in a rat model of Parkinson's disease. Analyst. $2015 ; 140: 3830-3839$.

3. Li C, Wang R, Chen H, Su W, Li S, Zhao X, Zhou J, Qiao J, Lou B, Song G and Chen M. Chemical Exchange Saturation Transfer MR Imaging is Superior to DiffusionTensor Imaging in the Diagnosis and Severity Evaluation of Parkinson's Disease: A Study on Substantia Nigra and Striatum. Front Aging Neurosci. 2015; 7:198.
4. Nagae LM, Honce JM, Tanabe J, Shelton E, Sillau SH and Berman BD. Microstructural Changes within the Basal Ganglia Differ between Parkinson Disease Subtypes. Front Neuroanat. 2016; 10:17.

5. van Bergen JM, Hua J, Unschuld PG, Lim IA, Jones CK, Margolis RL, Ross CA, van Zijl PC and Li X. Quantitative Susceptibility Mapping Suggests Altered Brain Iron in Premanifest Huntington Disease. AJNR Am J Neuroradiol. 2016; 37:789-796.

6. Stefanis L and Burke RE. Transneuronal degeneration in substantia nigra pars reticulata following striatal excitotoxic injury in adult rat: time-course, distribution, and morphology of cell death. Neuroscience. 1996; 74:9971008 .

7. Doya K. What are the computations of the cerebellum, the basal ganglia and the cerebral cortex? Neural Netw. 1999; 12:961-974.

8. Doya K. Complementary roles of basal ganglia and cerebellum in learning and motor control. Current Opin Neurobiol. 2000; 10:732-739.

9. Albin RL, Young AB and Penney JB. The functional anatomy of basal ganglia disorders. Trends Neurosci. 1989; 12:366-375.

10. Panula P, Chen YC, Priyadarshini M, Kudo H, Semenova S, Sundvik M and Sallinen V. The comparative neuroanatomy and neurochemistry of zebrafish CNS systems of relevance to human neuropsychiatric diseases. Neurobiol Dis. 2010; 40:46-57.

11. Flinn L, Bretaud S, Lo C, Ingham PW and Bandmann O. Zebrafish as a new animal model for movement disorders. J Neurochem. 2008; 106:1991-1997.

12. Soria G, Aguilar E, Tudela R, Mullol J, Planas AM and Marin $\mathrm{C}$. In vivo magnetic resonance imaging characterization of bilateral structural changes in experimental Parkinson's disease: a T2 relaxometry study combined with longitudinal diffusion tensor imaging and manganese-enhanced magnetic resonance imaging in the 6-hydroxydopamine rat model. Eur J Neurosci. 2011; 33:1551-1560.

13. Antonsen BT, Jiang Y, Veraart J, Qu H, Nguyen HP, Sijbers J, von Horsten S, Johnson GA and Leergaard TB. Altered diffusion tensor imaging measurements in aged transgenic Huntington disease rats. Brain Struct Funct. 2013; 218:767778.

14. Yang SH and Chan AW. Transgenic Animal Models of Huntington's Disease. Curr Top Behav Neurosci. 2011; 7:61-85.

15. Nilius B and Owsianik G. The transient receptor potential family of ion channels. Genome Biol. 2011; 12:218.

16. Moran MM, Xu H and Clapham DE. TRP ion channels in the nervous system. Curr Opin Neurobiol. 2004; 14:362369.

17. Alfonso S, Benito O, Alicia S, Angelica Z, Patricia G, Diana $K$ and Vaca L. Regulation of the cellular localization 
and function of human transient receptor potential channel 1 by other members of the TRPC family. Cell Calcium. 2008; 43:375-387.

18. Balch WE, Morimoto RI, Dillin A and Kelly JW. Adapting proteostasis for disease intervention. Science. 2008; 319:916-919.

19. Paschen W and Mengesdorf T. Endoplasmic reticulum stress response and neurodegeneration. Cell Calcium. 2005; 38:409-415.

20. Bezprozvanny I. Calcium signaling and neurodegenerative diseases. Trends Mol Med. 2009; 15:89-100.

21. Putney JW, Jr. and McKay RR. Capacitative calcium entry channels. Bioessays. 1999; 21:38-46.

22. Putney JW, Jr. A model for receptor-regulated calcium entry. Cell Calcium. 1986; 7:1-12.

23. Ambudkar IS. TRPC1: a core component of store-operated calcium channels. Biochem Soc Trans. 2007; 35:96-100.

24. Liu X, Cheng KT, Bandyopadhyay BC, Pani B, Dietrich A, Paria BC, Swaim WD, Beech D, Yildrim E, Singh BB, Birnbaumer L and Ambudkar IS. Attenuation of storeoperated $\mathrm{Ca} 2+$ current impairs salivary gland fluid secretion in TRPC1(-/-) mice. Proc Natl Acad Sci U S A. 2007; 104:17542-17547.

25. Selvaraj S, Sun Y, Watt JA, Wang S, Lei S, Birnbaumer $\mathrm{L}$ and Singh BB. Neurotoxin-induced ER stress in mouse dopaminergic neurons involves downregulation of TRPC1 and inhibition of AKT/mTOR signaling. The Journal of clinical investigation. 2012; 122:1354-1367.

26. Riccio A, Medhurst AD, Mattei C, Kelsell RE, Calver AR, Randall AD, Benham CD and Pangalos MN. mRNA distribution analysis of human TRPC family in CNS and peripheral tissues. Brain Res Mol Brain Res. 2002; 109:95104.

27. Bollimuntha S, Singh BB, Shavali S, Sharma SK and Ebadi M. TRPC1-mediated inhibition of 1-methyl-4phenylpyridinium ion neurotoxicity in human SH-SY5Y neuroblastoma cells. J Biol Chem. 2005; 280:2132-2140.

28. Selvaraj S, Watt JA and Singh BB. TRPC1 inhibits apoptotic cell degeneration induced by dopaminergic neurotoxin MPTP/MPP(+). Cell Calcium. 2009; 46:209218.

29. Haobam R, Sindhu KM, Chandra G and Mohanakumar KP. Swim-test as a function of motor impairment in MPTP model of Parkinson's disease: a comparative study in two mouse strains. Behav Brain Res. 2005; 163:159-167.

30. Sedelis M, Schwarting RK and Huston JP. Behavioral phenotyping of the MPTP mouse model of Parkinson's disease. Behav Brain Res. 2001; 125:109-125.

31. Liu Y, Yuan YH, Sun JD, Li J, Li ZP and Chen NH. Nigrostriatal dynein changes in A53T alpha-synuclein transgenic mice. F1000Res. 2014; 3:68.
32. Fink AJ, Croce KR, Huang ZJ, Abbott LF, Jessell TM and Azim E. Presynaptic inhibition of spinal sensory feedback ensures smooth movement. Nature. 2014; 509:43-48.

33. Xing R, Zhang Y, Xu H, Luo X, Chang RC, Liu J and Yang X. Spatial memory impairment by TRPC1 depletion is ameliorated by environmental enrichment. Oncotarget. 2016; 7:27855-27873. doi:10.18632/oncotarget.8428.

34. Ma X, Turnbull PC, Crapper EP, Wang H, Drannik A, Jiang F, Xia S and Turnbull J. Cytosolic localization of Fox proteins in motor neurons of G93A SOD1 mice. Histochem Cell Biol. 2016; 145:545-559.

35. Zuccato C, Liber D, Ramos C, Tarditi A, Rigamonti D, Tartari M, Valenza M and Cattaneo E. Progressive loss of BDNF in a mouse model of Huntington's disease and rescue by BDNF delivery. Pharmacol Res. 2005; 52:133139.

36. Lanzillotta A, Porrini V, Bellucci A, Benarese M, Branca C, Parrella E, Spano PF and Pizzi M. NF-kappaB in Innate Neuroprotection and Age-Related Neurodegenerative Diseases. Front Neurol. 2015; 6:98.

37. Shin E, Rogers JT, Devoto P, Bjorklund A and Carta M. Noradrenaline neuron degeneration contributes to motor impairments and development of L-DOPA-induced dyskinesia in a rat model of Parkinson's disease. Exp Neurol. 2014; 257:25-38.

38. Wang M, Li M, Geng X, Song Z, Albers HE, Yang M, Zhang X, Xie J, Qu Q and He T. Altered neuronal activity in the primary motor cortex and globus pallidus after dopamine depletion in rats. J Neurol Sci. 2015; 348:231240 .

39. Bollimuntha S, Ebadi M and Singh BB. TRPC1 protects human SH-SY5Y cells against salsolinol-induced cytotoxicity by inhibiting apoptosis. Brain Res. 2006; 1099:141-149.

40. Tatton NA. Increased caspase 3 and Bax immunoreactivity accompany nuclear GAPDH translocation and neuronal apoptosis in Parkinson's disease. Exp Neurol. 2000; 166:2943.

41. Thompson CB. Apoptosis in the pathogenesis and treatment of disease. Science. 1995; 267:1456-1462.

42. Naoi M and Maruyama W. Future of neuroprotection in Parkinson's disease. Parkinsonism Relat Disord. 2001; 8:139-145.

43. Willard AM, Bouchard RS and Gittis AH. Differential degradation of motor deficits during gradual dopamine depletion with 6-hydroxydopamine in mice. Neuroscience. 2015; 301:254-267.

44. Dobrivojevic M, Habek N, Kapuralin K, Curlin M and Gajovic S. Kruppel-like transcription factor 8 (K1f8) is expressed and active in the neurons of the mouse brain. Gene. 2015; 570:132-140. 